\title{
FOREIGN/SECOND LANGUAGE EDUCATION AND TECHNOLOGY IN THE FUTURE
}

\author{
Norman F. Davies
}

In my various roles as administrator and teacher, editor of a journal devoted to educational technology and language learning (System), and advisor on educational technology to Pergamon Press, I endeavour to keep in touch with development in both educational theory and educaional resources. I am not, in fact, very technically minded; I am concerned less with technological wonders as such than with the role they can play in educational systems. The task of educational technology is precisely to identify learner - and indeed teacher - needs and to develop or select, test and improve a full range of learning resources, whether they be technical, methodological or human. It must also concern itself with the proper training of educators and administrators, to see that optimum use is made of those resources. This task, I feel, has been rather neglected in the past, but is of crucial and ever-growing importance.

Furthermore any discussion on technological aids must ultimately take place within and be subordinate to the broader field of educational theory and practice, in our case as applied to language learning.

Too often in the past, 'technology has outrun the teacher', as Joseph Sheehan put it in a recent article; that is, the technology has existed and (some) teachers have wondered how to use it, whereas ideally as a profession we should be saying "we have these problems, these methods, these requirements; how can technology help us and what specifications should we ask the manufacturers to embody in their products?" And we should not let our enthusiasm and love of gadgetry cloud our sober judgement of what is appropriate and, not least, cost-effective. The educational equivalents of electric toothbrushes and talking cookers tend to run rather expensive.

In what I have to say here today, I am going to ignore interesting technical experiments by gifted technologists and locally successful multimedia courses such as we have heard described at conferences. I intend to concentrate on media and systems that are, or I expect will be, generally available for the average teacher and average learner, especially in schools. This may make my appraisal a rather sober one. In the heyday era of the audio-lingual method, teachers became much more active in the classroom - in fact, I'm afraid they did most of the talking. In addition, the method relied on audio-visual media, of which the language laboratory was by far the most prestigious, and by far the most expensive. Teachers found themselves seated behind consoles like railway traffic controllers, faced, for all too short a time, alas, by rows of eager faces expecting modern science to talk the ears out of learning French or whatever. Unfortunately, all this expensive equipment needed feeding with programs, and the library cupboard was bare. The manufacturers had nothing to offer; the teacher had, at best, received instruction in which buttons to press, but knew nothing about making programs. It was not uncommon to see hardware costing tens of thousands of dollars used to 
transmit the odd program from school radio and perhaps the recorded reading passages from the current textbook, with no very clear advantage gained over a single tape recorder in the classroom. Or pupils did mimicry and memorization or pattern drills to develop automatic responses, the most common of which, I suspect, was the 4-phase yawn, with responses as mechanical as the stimuli, which were stimulating only in a strictly Pavlovian sense. Furthermore, the machinery was far from pupil-proof, and teachers grew tired of a laboratory which could rarely work at full capacity. Disillusionment was complete when a number of investigations in the late 1960s, such has the Pennsylvania Foreign Language Research Project and the York Study, seemed to show that the language laboratory, as commonly used in schools at the time, had no measurable effect on pupils' subsequent performance. ${ }^{2}$

This is all well-known and my excuse for boring you with it is my belief that we are on the threshold of a new technological invasion of the school premises far more significant than any since the development of printing. I refer, of course, to the computer, more specifically in its miniaturized form. Have we learned the lessons of the past? Are we in the profession as a whole more prepared than we were when tape recorders were expected to revolutionize the teaching of languages?

Before speculating on future technology, however, I think I should like to dwell for a few minutes on trends in the use of the technology now widely available, with its problems and possibilities.

Let us stay with the language laboratory for a while. There is no doubt that the latest generation of electronically operated systems are more reliable, more flexible, quieter by far and much easier to use than the laboratories of the $60 \mathrm{~s}$, which were little more than domestic recorders built into rattling carrels. The great improvement in tape cassettes also means that the days of the reel-to-reel recorder are numbered, except, of course, for program making and editing. With the older equipment, technical problems and untechnical students could sometimes demand most of the supervisor's time during a lesson. Our own recently installed electronic cassette laboratory seems so far to have virtually banished all such problems, and is simplicity itself to operate. Wireless headsets have appeared on the market; I have no experience of their operation, but if they prove successful, comfortable to wear and not too expensive, they could overcome another common source of functional weakness.

At the same time as the technology has advanced, so has our understanding of the sort of tasks the language laboratory is best fitted for. while our evaluation of the contribution it may reasonably be expected to make to language learning has become much more realistic. In the light of recent research into the psychology of second language acquisition, emphasis is increasingly being laid on the importance of providing a large input of natural language from which the student can use the intake that he requires at his individual stage of development. Other linguists, including myself, have adduced evidence to show that initial emphasis in a language course should be on the receptive skills, with speech production being delayed until a stage of speaking readiness has been achieved. ${ }^{4}$ The 
most important present and future task of the language laboratory, I am therefore convinced, is in training listening comprehension, a much neglected skill, presenting the student with a variey of voices, dialects and levels of language, preferably in authentic and natural situations, which he can work with at his own pace.

If this were its only function, it would, of course, be sufficient to have a simple audio-passive system. The laboratory may, however, also be used for drills, provided they are short and demand active processing of language, not mere mechanical response. Work covered in class can be reinforced in the laboratory with new tasks, exploiting the main adviulus: of the system, which is that it allows everyone in a class to be active simultaneously. This is also why it should be used to encourage students to train their fluency, in guided conversations or in open-ended drills where the actual activity of expressing themselves, using the interlanguage they have acquired, is the central goal, and the teacher's urge to allow. only correct speech in his classroom should be firmly squashed.

A further valuable use of the laboratory is in discrimination exercises: in grammar, to train the self-monitoring ability, as proposed by Nords; in phonetics, to sensitive students to phonemic and supra-segmental features of the target language, so that they can then monitor their own attempts to reproduce its sound patterns. Pronunciation practice is, incidentally, one of the few times when students voluntarily use the comparative mode which is so expensive a feature of laboratory equipment. It is also one of the few exercises which 1 believe the teacher should monitor, to ensure pupils are actually doing what they believe they are doing, especially in the use of stress and intonation.

Otherwise I do not believe that lab monitoring by the teacher is custeffective. Any errors heard on the intercom will probably be random; immediate correction will interrupt the student, later correction may have little effect. If the teacher allows monitoring to be built into the program where practicable and elsewhere relies on self-monitoring hy the students, however faulty, he will make better use of his time by devoting himself to a small number of students needing individual attention, for whatever reason. There is no real call to design laboratories as rooms filled with carrels; if the booths are aligned along the walls, space can be freed for tables in the centre around which small groups can work, with or without the teacher. Or the electronic classioom with a portable master console may be used. Forty minutes concentrated work at a recorder, which is the usual 'lab period' format, almost certainly demands too much of the concentration of at least young leamers, and rotation within the class is preferable.

The final use of the language laboratory in its present forn that I should like to mention is self-study. This is likely to be a growing sector in the fulure, and already, many language centres offer study packages, particularly in the lesser-taught languages. ${ }^{6}$ If a person living in Stockholm or Manchester has a sudden need to learn Bemba, a self-study package is probably his only hope. There is a need for multi-media materials of this type, which should be available at regional learning centres throughout 
the world. I should like to see the production of minority language materials being subsidized by Unesco, aid organizations, foundations, universities, governments, industry and others. The American National Association of Self-Instructional Language Programs (NASILP) was constituted in 1972 to foster precisely these aims. The time is coming when a combination of text, tape, microcomputer and perhaps video will offer the highly motivated learner an efficient and flexible means of attaining a basic communicative competence in a target language. More restrïcted special purpose courses, such as a reading knowledge of Russian or German for scientists, are already on offer at language laboratories in some centres. ${ }^{\mathrm{a}}$ The market is undoubtedly there; I hope the future will provide the materials on a much wider scale.

Various complementary configuration of media can be, and have been added to the basic laboratory. The most unusual I have come across is the conjunction of learning laboratory and planetarium in Maine, but this is likely to remain an exception! 9 We have in this conference heard many accounts of the use of video, and the Cambridge laboratories, for instance, report considerable success with linked television screens, used for anything from teaching Chinese graphemes to showing close-ups of the teacher's mouth in pronunciation training. ${ }^{10}$ Tapeslide linkages are perhaps more common, being cheaper both to produce and to screen, and are often sufficient to provide the situational context required by the audio program." With both video and slide or film projection, however, we meet the vicious circle of cost and availability. The vast majority of language laboratories use commercially produced materials. As these laboratories do not have linked video or projection facilities, there are few viable markets for integrated audio-visual programs, and as the programs do not exist, there is no call to install the expensive facilities required. In fact, the cost of allowing each student in a class to have his or her own display is prohibitive both in hardware and software, and if all are. watching a central screen, then individual headsets and recorders are probably unnecessary. The soundtrack can, of course, be recorded separately and worked over later, which is an uneasy sort of compromise. The essence of full audio-active comparative facilities is the opportunity they give for individual pacing and feedback. I doubt therefore if the average language laboratory in any but some major language centres will alter its basic configuration much until the microcomputer has replaced the tape recorder as the central facility. I shall return to this possibility later.

By now, in the industrialized countries at least, most young people seem to own a cassette recorder. Ought we not in the future to make far greater use of this fact? Should it not be normal for each pupil to have his own cassette to accompany his textbook, to take home listening comprehension for assignments or for fun, to borrow or copy tapes from the tape library? My own department makes great use of cassettes in distance teaching ${ }^{\prime 2}$ and our contact students may hand in their own tapes to have any of our uncopyrighted stock recorded for their private use. 
Another scheme I should like to see developed on a wide scale is the cassette exchange, whereby pupils or groups of pupils in different countries would exchange cassette messages, rather as they have sometimes exchanged letters in the past. This would provide authentic materials at the right level of interest, and help to increase the language sample which pupils have to work on. When I try to persuade practicing teachers to introduce far more language into their classroom, I usually ask them to read aloud the total amount of texi in their current textbook. It will probably take them an hour or so, and yet that is what they and their pupils are going to spend a year on. This textual poverty must be overcome, and much more language must be heard, read and worked over if acquisition is to be given a reasonable chance. Cassette recorders should be a valuable aid in this.

Television has been with us for longer than the language laboratory; the videorecorder, on the other hand, is scarcely ten years old in a format suitable for the consumer market. Major broadcasting systems have considerable expertise in producing language and other programs on both radio and television, and television is really excellent for bringing to life the cultural background to language. At the same time, television is expensive, and the language programs that are produced tend to be full courses of the type "Tourist Italian' or 'Brush Up Your English', where the broadcasting company can sell a course book and expect an audience of thousands. The modular programs that are to be found on the school radio, which teachers can use as and when they fit in with their courses, are in my experience rare on television. Furthermore, videotape is relatively expensive, and many schools cannot afford to keep a large stock of library programs. One way to overcome this is the system used in Sweden, for instance, where there are local AV-centres financed by the educational authorities which record school radio and television, and from which teachers may borrow the programs they require. Such a system greatly increases the use of audio-visual media by teachers who might otherwise lack the initiative to arrange their own rècordings. Television language courses are likely to grow considerably in extent in the future. perhaps in combination with text TV, which can screen the textbook, so to speak.

As for commercial video, the picture is much less bright. Very few lextbooks indeed have a video component; I know of no courses based on video apart from those that have been broadcast previously by the BBC or other European networks, for instance. ${ }^{13}$ Video modules, especially with a situational or functional approach, could be very valuable; nothing makes a situation as real as seeing it, and television can contextualize language in a way no textbook or even audio tape ever can. Sume teachers will make their own viden programs; the vast majority will not, and in the r.tin of videcodiscs, cannot. But there are at present two obstacles in lhe way of grcater use of professional video, apart from the fact that we still have much to learn on the best methods to exploit the medium.

The first obstacle is cost. The cost of the hardware is itself considerable, but the unit costs of making programs in a proiessional way are also very high. Pergamon Press recently received an estimate for a 
television-making firm for a 10-minute English film using a couple of locations and three or four actors. The estimated cost was about $\$ 14,000$. They had a series of ten programs, which would reduce unit costs, admittedly, but you have to be sure of a large market before you can accept expenses of that order.

And that brings us to the other problem: the competing and mutually incompatable video systems at present on the market. Two years ago, if you had asked a dealer which system was most likely to dominate in the future, he would doubtless have told you VCR. VCR sets have now gone the way of SVR, and are no longer mode. Today we have three tape systems to choose from, to my knowledge: VHS, Beta or U-matic and V2000, while the videodisc has recently appeared in two or three incompatible versions.

But for the commercial publisher of language programs, which after all do not have the popular appeal of blood and sex, the problem remains: which system should he back? In other words, I think we must hope that one system finally triumphs over the others and becomes the standard before the language video market can really be expected to flourish. This will probably happen in time, and it may well be none of the models at present available.

But let us now turn to the technology that is in process of revolutionizing our lives and even our social organization. The first Industrial Revolution is generally thought to have taken some eighty years, from 1750-1830, to have brought about really radical change in society; if that was a revolution, then I suppose we must talk of the computer convulsion, a violent upheaval and agitation of society to which it may take us a long time to adjust. This is especially so since the advent of microelectronics, which by the end of this century, if not indeed of this decade, will have transformed almost every branch of industry, commerce, administration and, can one doubt it, education.

In Britain, for instance, the Council for Educational Technology for the UK has launched a National Microelectronics Development Programme, 1980-1984, intended to 'serve the needs of education and industry by helping schools and colleges to make better use of micro-electronics as a teaching resource and to equip young people with the skills ... required'14, while the BBC has launched its Computer Literacy Project, starting in January 1982. This will not merely explain the workings and the uses of the new technology, but will be linked to a course in programming on a specially designed BBC microcomputer. A range of programs (in BASIC) will be developed for this computer.

In other words, the computer is on its way into schools. Where money is short, what funds are available will be spent not on language laboratories but on microcomputers. And once again, there is little doubt that technology is going to outrun at least the teacher of languages. For, as in the universities, the computers will not be installed for the benefit of language studies. When the British Schools Council examined how the computer could assist the teaching of subjects other than mathematics, 
they looked at biology, chemistry, physics, geography and economics. Not French or German or Spanish.

Now we all know that computer assisted instruction in language learning is flourishing in many centres, though these are rarely in schools. The computer offers many advantages for individualized instruction: it has infinite patience and often an attractive 'personality' (usually the teacher's own idealized view of himself); it can diagnose, test and retest a pupil's weaknesses; it allows branching to deal with individual' errors, which the tape recorder cannot do; it gives the pupil a sense of being in control without needing to feel embarassed at his own weaknesses. At the same time, computers in the past have been too large and too expensive for any but the universities; they have had fixed terminals perhaps far from the language schools; there have been fairly complicated procedures for logging in and logging out; many have lacked a visual display. Also, programming these computers has required special skills that most teachers have felt to be too demanding.

The microprocessor and the microchip will soon change all this. We have seen the price of pocket calculators, for instance, drop startlingly over recent years; we have seen things the size of $a^{+}$wrist watch or a pen top outperform the large desk-top machines of a decade ago. Technology is offering us - I might almost say forcing upon us - the unlikely combination of revolutionary possibilities at low cost. We have heard many of the predictions for the future, not all of them obviously attractive: the disappearance or the book, for instance, and even of libraries, or of the ordinary shop, or of millions of jobs. But al'ready we have portable microprocessors with a colour screen available on the market; fed with a diskette, they are as easily loaded and accessed as a cassette recorder. The screen can reinforce the printed message in many ways, allowing graphics, illustrations, animated displays, colour-keyed grammatical explanations. ${ }^{13}$ At the moment the written mode predominates, though the computer can be linked with a cassette recorder, for instance, for a dictation exercise which the computer marks.

There are other foreseeable developments, however, which will greatly increase the use of microprocessors for language instruction. One is an improvement in programming routine giving greater economy of use and the capacity to accept instructions in natural language.

But more important is going to be the development of what we may call the 'voice chip'. Programmers would dearly love to talk to their machines; the possibility already exists, and is likely to be developed very rapidly. But a one-sided conversation is unsatisfactory to all but the most egocentric of us. There are already educational toys on the market for improving vocabulary or talking tourist phrase books which can be accessed at random, but soon speech synthesis by microcomputer will be a reality. We shall then have an interactive language teacher of infinite patience, who is never sarcastic or loses his temper, who will repeat a phrase or a sound as often as the pupil wants, who can perhaps be consulted at home or on the bus, and who can be switched off and put in a drawer when the learner has had enough. Instead of an en- 
thusiastic teacher laboriously writing program $X$ i., Sydney while a colleague equally laboriously works out a similar programme in Kyoto, (both reinventing the wheel, so to speak) in the near future a wide range of diskettes will be available on the market and later instruction manuals will show how to talk into the computer a great variety of exercises, tests, guided conversations, comprehension passages and more.

At least, that is how it ought to be. As I said before, computers are not developed with the language teacher in mind, but once they start to speak, we will find it impossible to ignore them. Will we as a profession be prepared? Will we be able to tell the manufacturers what we want? Will applied linguistics and experienced teachers be ready to put onto the market good, well thought out language programs or will commercial gimickry carry the day? How far will we let technology outrun us? There is, I think, good cause to wonder, for even today, many trainee teachers are given very inadequate training in the media we dispose of at present, often because their teachers have had no training.

A recent book on what it calls the 'micro millenium' has, in a section dealing with 'The Middle-Term Future', i.e. 1983-1990, a chapter called "The Decline of the Professions.'18 Computers, it is claimed, will make available to everyone the knowledge laboriously acquired and jealously guarded by the traditional professions such as medicine, law and teaching, which will therefore gradually wither away or lose in status and importance.

Personally, I doubt it. This is perhaps because I come from a society which has long suspected revolutions and has found gradual change more human, more comfortable, and sometimes even more efficient. But gradual is a relative term; I do not think we have much time before we are forced to adjust or perish. We need, as a profession, to unite and face with honesty this challenge to our present ideas and methodologies. If we come to terms with the computer and learn how best to use it, we may steer developments instead of falling victims to them, and our profession will find itself in possession of a most powerful tool and ally.

Let us remember that the amount of foreign language learning rrtually done in many societies is very small indeed, yet the number of people who would like to learn is huge. Let us admit that our success rate today is often very poor. The new technology may open new markets, lead to an upswing in enrollments. And I do not doubt that teachers will still be needed, for the essence of language is human contact and its expression is unpredictable. Machines can only deal with the foreseen; they will never, for instance, be able to evaluate satisfactorily creative writing, conduct an ordinary conversation or take the students on an excursion. But I repeat, we must learn how to use them, and we must be prepared, if necessary, to abandon our traditional roles and expectations. A recent paper in the British Journal of Educational Technology quoted the example of the Australian aboriginal tribe, whose trade and even social structure was founded on the making, borrowing and exchange of stone axes. When missionaries provided steel axes, it upset the social structure. On the other hand, they used the steel axes only 
for tasks for which they had previously used the stone axes. The time they saved they spent sleeping. ${ }^{17}$ If this is how we,, as a profession, use the new technology, we will indeed go into decline, and deservedly.

The microcomputer is not going to work miracles; there is no French without tears, or at least hard work, but, finally, let us determine to exploit imaginatively a technology that will substantially assist our profession in its central and, in our time, so essential task of helping people the world over to understand and talk to each other.

'Joseph H. Sheehan, 'The Language Laboratory' NALLD Journal 15/1, Fall 1980, p. 10

2Paper given at the First International Conference on Foreign Language Education and Technology, Tokyo, Japan, 18-21 August, 1981

see eg. J. B. Carroll, 'What does the Pennsylvania Foreign Language Research Project tell us?' Foreign Language Annals 3, 1969, 214-236 Peter S. Green, (ed), The Language Laboratory in School. Performance and Prediction. An Account of the York Study. Edinburgh: Oliver and Boyd, 1975

Norman F. Davies

Department of Languages \& Literature University of Linkoping 58183 Linkoping, Sweden

\section{FOOTNOTES}

${ }^{3}$ See eg. Stephen Krashen, Second Language Acquisition and Second Language Learning. Oxford: Pergamon 1981

${ }^{4} \mathrm{~A}$ summary of the case and a bibliography can be found in Norman F. Davie Putting Receptive Skills First: An Investigation into Sequencing in Modern Language Learning. University of Linkoping, 1978

5James R. Nord, 'The Sens-it-Cell: System 3/1, January 1975, 16-23

${ }^{6}$ See e.g. D. E. Ager, E. Clavering and J. Galleymore, 'Assisted SelfTutoring in Less Taught Languages', Canadian Modern Language Review 36/3 March 1980, 468-480

David Dwyer, "The African Language Program at Michigan State University" System 7/1, March 1979, 7-27

7See John B. Means, 'The National Association of Self-Instructional Language Programs: A Brief Overview', System 7/1, March 1979, 43-44

'Adele B. Hernandez, 'Learning Lab-Planetarium Innovation', System 4/3, October 1976, 198

"e.g. N. Messora and B. Sherill, 'A New Role for Audio-Visual Aids: A Slide-Sequence of Strategies and Protocols', System 6/2, May 1978, 79-88 
'2See e.g. Norman F. Davies, 'Language Teaching at a Distance: A Challenge to the University Department', IRAL XV/3 (1977), 239-245

${ }^{13}$ The most ambitious is probably Follow Me! co-produced by German Austrian and Swiss network and the BBC, based largely on the Council of Europe's Waystage and Threshold Level specifications.

${ }^{14}$ CET News 9 (March 1980)

15 For an interesting account of the use of such a microprocessor, see G. Holmes and M. Kidd, "Serving Learner Needs: From Teletype to Micro", System 9/2, May 1981

${ }^{18}$ Christopher Evans, The Micro Millenium. New York: The Viking Press, 1979

17G. J. Bleumenfeld, J. J. Hirschbuhl and A. A. Al-Rubaiy, "ComputerBased Education: a case for planning culture change in the school" British Journal of Educational Technology 10/3, October 1979, 186-7

\section{International Association of Learning Laboratories} NALLD JOURNAL

New Advances in Learning Laboratory Development

Name MEMBERSHIP

APPLICATION

Title

New Mumber North American U.S./Can/Mexico

Institution All libraries +

Address to which NALLD JOURNAL is to Foreign air mail

be sent:

Students

Address

Sustaining Members

City State ..... Zip

Return this form to:

NALLD JOURNAL Academic Publications Administration Building University of Louisville, KY 40292 


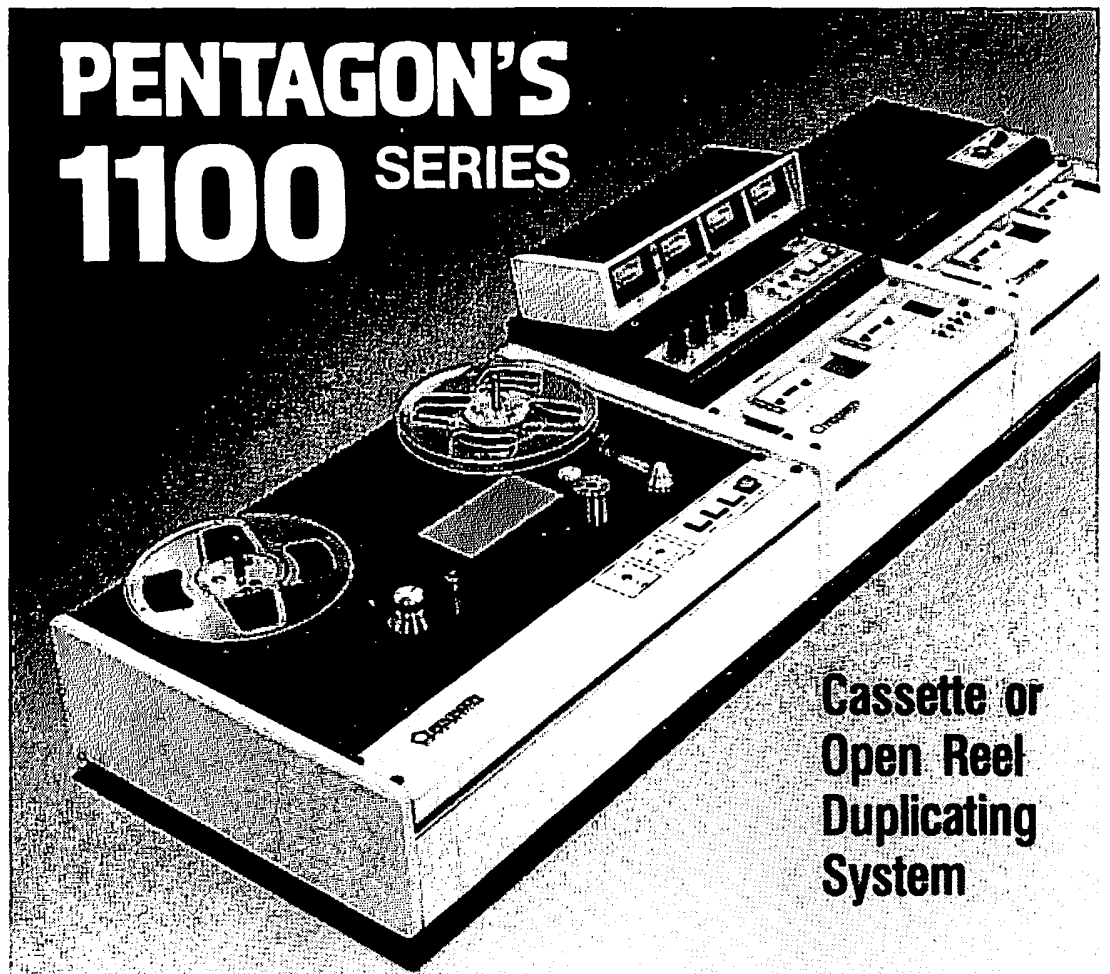

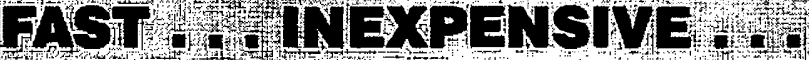 \\ 30J140)1ST}

After careful evaluation of the capabilitites and performance of Varifous tape duplicating systems: over 10,000 users all over the world have selected is on tag on equlp: ment

This system 100 " provides the Liser with exceptional versatility and istate: of the art design tor high (16x) sspedi cassette duplication: Beginuithitho icassolte to cassette nodule. unit or adititonal cassette slaves or reeilstaves as required: An Iili slave postion isystem will hroduce up to 4500 (100 minute) cassette or reel coples per day.
Sone groat foeathros inghted push button

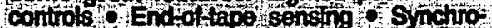

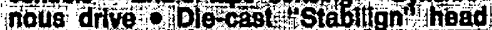
mounts o Track is of ect o Automatic rewind on

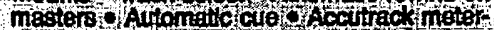

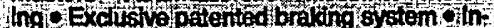

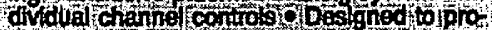
Yoot mister topes:

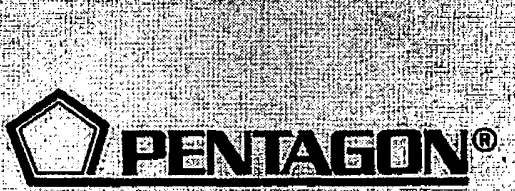

Woitd Keadquantere 4751 North Olcot Chicago 111460656

(B12) 8679200

$1 \times 25-3058$

TolliFree 18006713867 


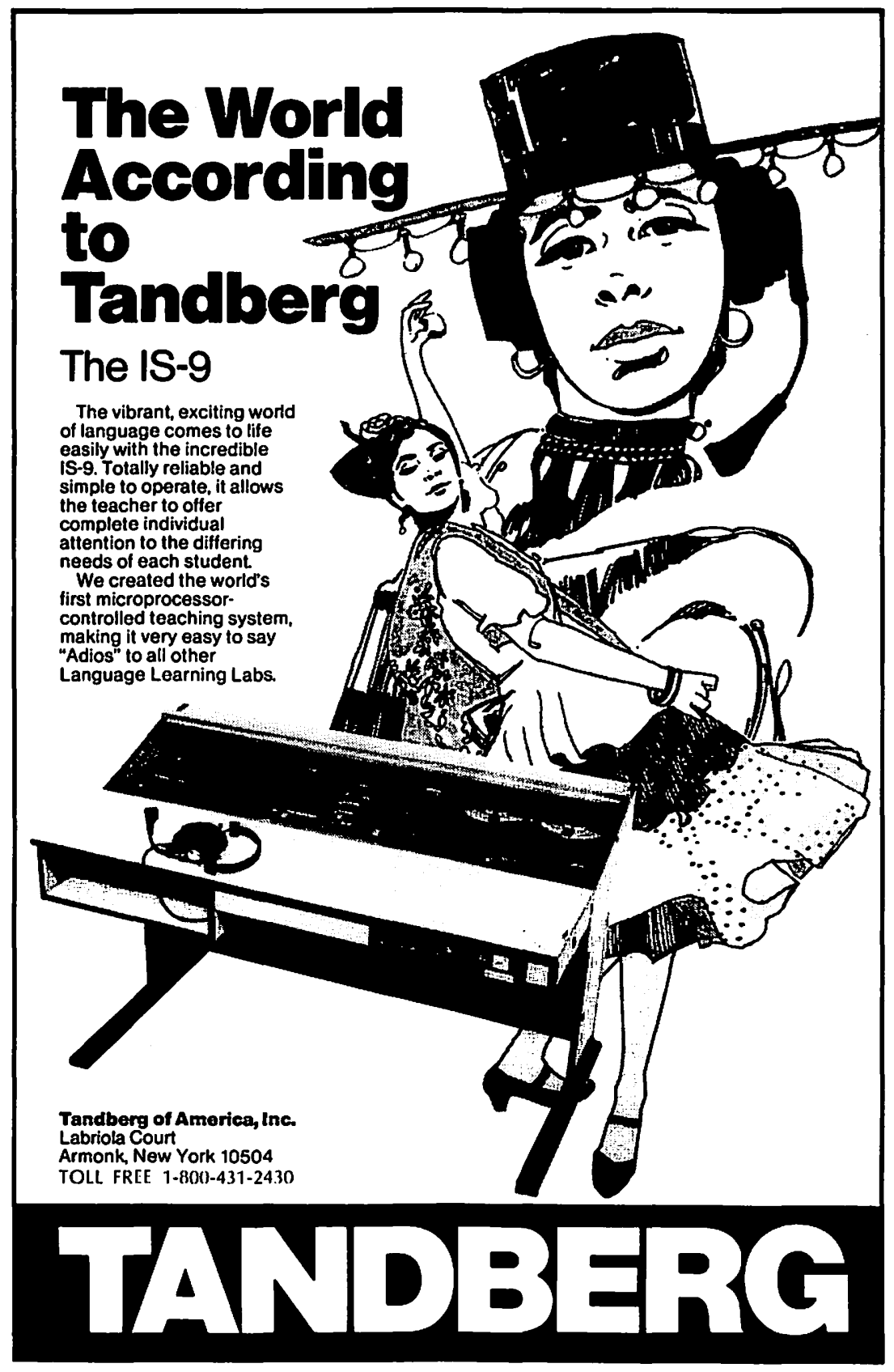

